\title{
Effect of Individual Sulfide on the Stability against Oxidation of Transformer Oil and Its Electrical Parameters
}

\author{
Gainullina L.R. \\ Kazan State Power Engineering University \\ Kazan, Russian Federation
}

\begin{abstract}
This study is devoted to the improvement of the transformer oil quality, using a new inhibiting additive, since the extensively used inhibitory additive ionol is sensitive to organosulfur compounds of sulfur oils. From the earlier works, the organosulfur compounds are known to affect ambiguously the transformer oils characteristics. Therefore, it was of interest to study the individual sulfides as the inhibitory additives. The goal was achieved by the researches with the use of the model mixtures consisting of the selectively purified transformer oil (free from ionol) along with the individual sulfides, decylcyclohexylsulfide and decylfenylsulfide, at concentration of $0.5 \%$, Their effect on stability against oxidation of the selectively purified oil, on its electric strength and tangent of the dielectric losses' angle was studied. The primary results obtained were, firstly, the rate slowing down of water formation in oil and of water-soluble acids formation in oil upon its oxidation in the presence of the individual sulfides, and, secondly, an increase in the electric strength and decrease in the dielectric losses compared to the transformer oil, containing ionol. It was established that decylcyclohexylsulfide inhibitory properties are stronger compared to those of decylfenylsulfide, which was testified by less quantities (by 1.8 times) of the water formed and of water-soluble acids (by 2.22 times). The introduction to oil of $0.5 \%$ decylcyclohexylsulfide and decylfenylsulfide increased the oil electric strength, correspondingly, by 2.6 and by 5.5 times, upon water concentration in oil equal to $15 \cdot 10^{-2} \mathrm{~g} / \mathrm{kg}$. The significance of the results obtained is in improving the transformer oil quality produced from the sulfur oils with the use of a novel additive.
\end{abstract}

Keywords: dielectric strength, dielectric loss, individual sulfide, additive, oil insulation, decylcyclohexyl sulfide, decylphenyl sulfide.

DOI: https://doi.org/10.52254/1857-0070.2021.4-52.03

UDC: 621.3.048.82, 665.61

\section{Influența sulfurilor individuale asupra stabilității anti-oxidare a uleiului de transformator și a proprietăților sale electrice Gainullina L. R. \\ Universitatea Energetică de Stat din Kazani Kazani, Federația Rusă}

Rezumat. În timpul exploatării proprietăţile fizico-chimice şi indicatorii electrofizici ale uleiului de transformator se înrăutățesc proprietățile electroizolante se pierd parțial sau total. Pentru încetinirea procesului de oxidare a uleiului și, respectiv, stabilizarea indicatorilor fizico-chimici este utilizat ionolul. Scopul lucrării constă în creșterea calităţii uleiului de transformator prin introducerea unui nou aditiv inhibitor, deoarece cel mai răspândit aditiv inhibitor, ionolul, este sensibil la compuşii organici sulfuroși din uleiurile sulfuroase și cu conținut ridicat de sulf, din care se produc fracțiunile de ulei. Obiectivul a fost atins prin cercetarea unor amestecuri model, ce constau din ulei de transformator purificat selectiv (fără ionol) şi sulfuri individuale, sulfură de deciclohexil și sulfură de decilfenil, la o concentrație de 0,5\%. A fost studiată acțiunea lor asupra stabilităţii anti-oxidante a uleiului de purificare selectivă, asupra durităţii electrice și a tangentei unghiului de pierderi dielectrice. Cele mai importante rezultate sunt încetinirea vitezei de formare a apei în ulei și a acizilor solubili în apă în timpul oxidării acestuia în prezența sulfurilor individuale, precum și creșterea rigidității electrice și reducerea pierderilor dielectrice în comparaţie cu uleiul de transformator care conţine ionol. Este stabilit că deciclohexilsulfura posedă proprietăți de inhibare înalte comparativ cu decilfenilsulfura, fapt despre care denotă o mai mică cantitate de apă formată de 1,89 ori și de acizii solubili în apă de 2,22 ori. Introducerea în ulei a $0,5 \%$ de decilfenilsulfură şi deciclohexilsulfur crește rigiditatea electrică a acestuia de 2,6 și respectiv de 5,5 ori la o concentrație de apă în ulei egală cu 15-10-2 g/kg. Semnificația rezultatelor obținute constă în îmbunătăţirea calității uleiului de transformator obținut din uleiuri sulfuroase prin adăugarea unui nou aditiv.

Cuvinte-cheie: rigiditate dielectrică, pierderi dielectrice, sulfură individuală, aditiv, izolație de ulei, sulfură de deciclohexil, sulfură de decilfenil. 


\section{Влияние индивидуальных сульфидов на стабильность против окисления трансформаторного масла и его электрические показатели \\ Гайнуллина Л.Р.}

Казанский государственный энергетический университет

Казань, Российская Федерация

Аннотация. В процессе эксплуатации ухудшаются физико-химические свойства трансформаторного масла, его электрофизические показатели, частично или полностью утрачиваются электроизоляционные свойства. Для замедления процесса окисления масла и соответственно стабилизации физико-химических показателей применяется ионол. Целью работы является повышение качества трансформаторного масла за счет введения новой ингибирующей присадки, поскольку наиболее распространенная ингибирующая присадка ионол чувствительна к сераорганическим соединениям сернистых и высокосернистых нефтей, из которых производят масляные фракции. Из ранних работ известно неоднозначное влияние сероорганических соединений на характеристики трансформаторных масел, поэтому представляло интерес исследовать в качестве ингибирующей присадки индивидуальные сульфиды.

Поставленная цель достигается проведением исследований на модельных смесях, которые состоят из трансформаторного масла (без ионола) селективной очистки и индивидуальных сульфидов, децилциклогексилсульфида и децилфенилсульфида, в концентрации 0.5 \%. Было изучено их влияние на стабильность против окисления масла селективной очистки, на его электрическую прочность и тангенс угла диэлектрических потерь. Наиболее важными результатами являются замедление скорости образования воды в масле и водорастворимых кислот при его окислении в присутствии индивидуальных сульфидов, а также повышение электрической прочности и снижение диэлектрических потерь по сравнению с трансформаторным маслом, содержащим ионол. Установлено, что децилциклогексилсульфид обладает большими ингибирующими свойствами по сравнению с децилфенилсульфидом, о чем свидетельствует меньшее количество образовавшейся воды в 1.89 раза и водорастворимых кислот в 2.22 раза. Введение в масло $0.5 \%$ децилфенилсульфида и децилциклогексилсульфида повышает его электрическую прочность соответственно в 2.6 раза и в 5.5 раза при концентрации воды в масле, равной $15 \cdot 10^{-2}$ г/кг. Значимость полученных результатов заключается в повышении качества трансформаторного масла, получаемого из сернистых нефтей добавлением новой присадки.

Ключевые слова: электрическая прочность, диэлектрические потери, индивидуальные сульфиды, присадка, масляная изоляция, децилциклогексилсульфид, децилфенилсульфид.

\section{ВВЕДЕНИЕ}

Прогнозируется, что к 2030 году мировой рынок трансформаторного масла достигнет 3.3 млрд долларов США [1]. Факторами,способствующими увеличению производства трансформаторного масла являются расширение электрических сетей, а также модернизация, связанная с индустриализацией и урбанизацией. Расширение электрической сети приведет к установке новых трансформаторов и распределительных устройств, что в свою очередь приведет к увеличению спроса на трансформаторное масло.

Стабильность работы современных энергетических систем производства и распределения электрической энергии потребителям во многом определяется надежностью эксплуатации маслонаполненного электрооборудования, входящего в состав системы. В маслонаполненном электрооборудовании высших классов напряжения нефтяное трансформаторное масло широко применяется в качестве теплоотводящей и изолирующей среды. Поэтому, к основным требованиям, которые предъявляются к трансформаторному маслу, относятся электрическая прочность и тангенс угла диэлектрических потерь. В процессе эксплуатации трансформаторное масло подвергается одновременному воздействию электрического поля, высоких температур и кислорода воздуха в присутствии катализатора окисления (меди), приводящих к изменению физико-химических свойств масла (его старению). Вследствие этих изменений ухудшаются электрофизические показатели трансформаторного масла, частично или полностью утрачиваются электроизоляционные свойства. При эксплуатации масла в электрических машинах и аппаратах под воздействием кислорода воздуха, электрического поля высокой напряженности и повышенных рабочих температур, оно подвергается термохимическому и электрохимическому 
старению [2-6]. Этот процесс приводит к ухудшению эксплуатационных и электрических характеристик масла, поскольку при старении оно загрязняется твердыми частицами, кислотами, и в нем увеличивается газо- и влагосодержание, что может привести к аварийным повреждениям маслонаполненного электрооборудования, его разрушению, влекущим за собой нарушения электроснабжения и большому экономическому ущербу в энергосистеме и у потребителя [7-10]. В случае отказа трансформаторного оборудования высших классов напряжения с большой единичной мощностью возникают особенно большие экономические потери [11-13].

Электрическая прочность и диэлектрические потери, а также стабильность масла против окисления относятся к основным параметрам, определяющим свойства масла и его срок службы $[14,15]$.

Для замедления процесса окисления масла и соответственно стабилизации физикохимических показателей применяется ионол. Однако наиболее распространенная ингибирующая присадка ионол чувствительна к сераорганическим соединениям сернистых и высокосернистых нефтей, из которых производят масляные фракции [16-17]. Рост потребности трансформаторного масла вызвал необходимоть их производства из сернистых нефтей.

Сернистые соединения способствуют окислению углеводородов с образованием нерастворимого твердого осадка и сульфокислот. Окисление углеводородов и сернистых соединений трансформаторного масла происходит с образованием устойчивых гидропероксидов, кислот, альдегидов, смол, газов. Продукты окисления сернистых соединений являются сильными коррозионными агентами, особенно в присутствии меди, являющейся конструкционным материалом трансформаторов. Однако известно и противоположное действие некоторых сернистых соединений. Поскольку они обладают способностью реагировать с гидропероксидами и другими кислородсодержащими продуктами. Из ранее проведенных автором исследований известно, что количественное образование осадка определяется структурно-групповым составом сернистых соединений. В связи с увеличившейся долей добычи и переработки сернистых и высокосернистых нефтей, а также неоднозначностью влияния сероорганических соединений на характеристики трансформаторного масла

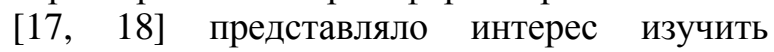
влияние интенсивности увлажнения трансформаторного масла селективной очистки на величину электрической прочности и диэлектрических потерь в масле в присутствии индивидуальных сульфидов.

\section{I. МЕТОДЫ ИССЛЕДОВАНИЯ}

Объектом исследования служило трансформаторное масло селективной очистки ТСп (ГОСТ 10121-76). Испытаниям подвергали масло, не содержащее в своем составе антиокислительной присадки ионола ТС. В качестве ингибирующей антиокислительной добавки были использованы индивидуальные сульфиды, имеющие различное строение децилциклогексилсульфид (ДЦГС) с молекулярной массой, равной 256, и эмпирической формулой $\mathrm{C}_{16} \mathrm{H}_{32} \mathrm{~S}$, и децилфенилсульфид (ДФС) с молекулярной массой 250 и эмпирическйо формулой $\mathrm{C}_{16} \mathrm{H}_{26} \mathrm{~S}$.

Электрическая прочность трансформаторного масла характеризуется пробивным напряжением в стандартном разряднике и определяется по ГОСТ 6581-75. Тангенс угла диэлектрических потерь также определяется по ГОСТ 6581-75.

Перед проведением эксперимента масло подвергалось тщательной очистке, осушке и дегазации, поскольку электрическая прочность масла и диэлектрические потери зависят от его газо- и влагосодержания и наличия различного типа загрязнений в нем [19-22].

Стабильность трансформаторного масла против окисления его углеводородов в электрическом поле напряженностью $30 \mathrm{\kappa B} / \mathrm{cm}$ изучали в аппарате, представляющем собой отдельную масляную секцию трансформатоpa. В аппарате находятся железные и медные пластинки, соответственно в количестве 0.3 $\mathrm{cm}^{3}$ и $0.2 \mathrm{~cm}^{3}$ на 1 г масла, имитирующие конструкционные материалы электрооборудования. Окисление углеводородов масла проводили по ГОСТ 981-75. Стабильность масла против окисления определяли по следующим показателям: количество поглощенного кислорода, содержание летучих низкомолеку- 
лярных кислот, показателям кислотного числа, и массовой доли осадка. Также были определены концентрация водорастворимых кислот и концентрация воды в масле.

Количество воды определяли по ГОСТ 7822-75. Опыты были проведены в присутствии и отсутствии индивидуальных сульфидов. Концентрация индивидуальных сульфидов во всех опытах составляла $0.5 \%$ на массу масла. Такая концентрация сульфидов обоснована в работах $[17,23]$.

\section{II. РЕЗУЛЬТАТЫ И ОБСУЖДЕНИЕ}

Влияние концентрации сульфидов на количество поглощенного кислорода представлено на рис. 1. При введении в масло селективной очистки индивидуальных сульфидов наименьшее количество поглощенного кислорода наблюдалось при их концентрации $0.5 \%$. Таким образом, в дальнейших экспериментах индивидуальные сульфиды добавляли в количестве $0.5 \%$.
Содержание летучих низкомолекулярных кислот, показатели кислотного числа, и массовой доли осадка, концентрация водорастворимых кислот и концентрация воды в масле после окисления представлены в таблице.

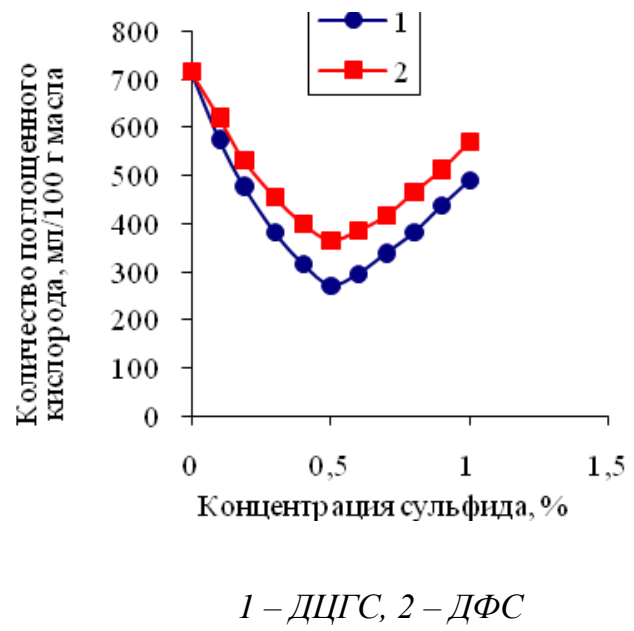

Рис. 1. Влияние концентрации сульфидов на количество поглощенного кислорода ${ }^{1}$

Таблица ${ }^{6}$

Показатели трансформаторного масла в присутствии индивидуальных сульфидов

\begin{tabular}{|c|c|c|c|}
\hline $\begin{array}{c}\text { Показатель } \\
\text { (Indicator) }\end{array}$ & $\begin{array}{l}\text { Трансформаторное } \\
\text { масло с ионолом } \\
\text { (Transformer oil } \\
\text { with ionol) }\end{array}$ & $\begin{array}{l}\mathrm{TC}+0.5 \% \text { ДФС } \\
(\mathrm{TS}+0.5 \% \mathrm{DFS})\end{array}$ & $\begin{array}{l}\mathrm{TC}+0.5 \% \\
\text { ДЦГС } \\
(\mathrm{TS}+0.5 \% \\
\text { DCGS) }\end{array}$ \\
\hline $\begin{array}{l}\text { Масса летучих кислот, } \\
\text { мг КОН/ г масла } \\
\text { (Mass of volatile acids, } \\
\text { mg KOH / g of oil) }\end{array}$ & 0.12 & 0.034 & 0.0089 \\
\hline $\begin{array}{l}\text { Кислотное число, мг } \\
\text { КОН/ г масла } \\
\text { (Acid number, mg КОН / } \\
\text { g of oil) }\end{array}$ & 0.25 & 0.16 & 0.0029 \\
\hline $\begin{array}{l}\text { Массовая доля осадка, } \\
\% \text { (Mass fraction of } \\
\text { sediment, \%) }\end{array}$ & 0.09 & 0.009 & 0.0009 \\
\hline $\begin{array}{l}\text { Концентрация } \\
\text { водорастворимых } \\
\text { кислот, мг КОН/ } 1 \text { г } \\
\text { масла } \\
\text { (Concentration of water- } \\
\text { soluble acids, mg KOH / } \\
1 \text { g of oil) }\end{array}$ & 0.01 & 0.006 & 0.0027 \\
\hline $\begin{array}{l}\text { Концентрация воды в } \\
\text { масле, г/кг } 10^{2} \\
\text { (Water concentration in } \\
\text { oil, g/ } \mathrm{kg} \cdot 10^{2} \text { ) }\end{array}$ & 15.0 & 10.0 & 5.3 \\
\hline
\end{tabular}


Из данных, приведенных в таблице, следует, что введение в состав трансформаторного масла $0.5 \%$ индивидуальных сульфидов ДФС и ДЦГС замедляет скорость образования воды в масле при его окислении. Так, например, при добавлении к маслу ТС $0.5 \%$ ДФС количество образовавшейся воды снизилось в 1.5 раза по сравнению с исходным маслом. Введение в масло ДЦГС $0.5 \%$ уменьшает количество образовавшейся воды в 2.83 раза по сравнению с маслом, содержащим ионол.

Из таблицы также следует, что наиболее оптимальной добавкой к маслу является индивидуальный сульфид ДЦГС, который снижает содержание воды в 2.83 раза по сравнению с маслом, содержащим ионол, и в 1.89 раза по сравнению с маслом, содержащим в своем составе $0.5 \%$ ДФС. Данный факт подтверждается также количеством образовавшихся водорастворимых кислот (таблица) в исследуемом масле в присутствии и отсутствии индивидуальных сульфидов.

По результатам проведенного эксперимента массовая доля осадка и кислотное число значительно уменьшаются в присутствии ДЦГС.

Из таблицы видно, что по всем показателям стабильности против окисления масла, во-первых,исследуемые сульфиды проявляют ингибирующие свойства, вовторых, замена в сульфиде ДФС ароматического радикала на нафтеновый радикал увеличивает ингибирующую способность сульфида.

К основным параметрам, определяющим свойства масла как диэлектрика, относятся электрическая прочность и диэлектрические потери в масле (тангенс угла диэлектрических потерь). В этой связи, представляло интерес исследовать влияние индивидуальных сульфидов, ДФС и ДЦГС, на электрические показатели трансформаторного масла.

Следующая серия опытов была проведена с использованием модельных смесей (трансформаторное масло - вода). Основу смесей составляло масло ТС, к которому добавляли дистиллированную воду, взятую в количестве от 0 до $15 \Gamma /$ кг $10^{-2}$ масла с шагом $2 \cdot 10^{-2} \quad$ г/кг масла. При проведении исследования в трансформаторное масло ТС без ионола были добавлены сульфиды ДФС и ДЦГС. Изучено влияние воды на электрическую прочность масла. Для сравнения были измерены показатели электрической прочности для масла, содержащего ионол.

Результаты проведенного эксперимента в виде графических зависимостей приведены на рис. 2 .

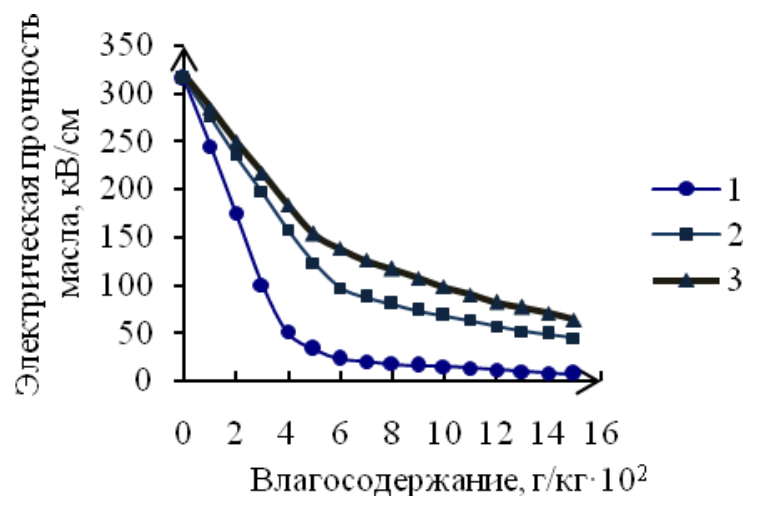

1 - трансформаторное масло с ионолом, 2 масло ТС + $0.5 \%$ ДФС, 3 -масло ТС $+0.5 \%$ ДЦГС

Рис. 2. Влияние содержания воды в масле на его электрическую прочность ${ }^{2}$

В соответствии с экспериментальными данными, приведенными на рис. 2, растущая концентрация воды в исходном масле приводит к снижению величины электрической прочности его в 16 раз. Вместе с тем, как видно из рис. 1, введение в масло $0.5 \%$ ДФС и ДЦГС несколько снижает падение его электрической прочности соответственно в 2.6 раза и в 5.5 раза при концентрации воды в масле, равной $15 \cdot 10^{-2}$ г/кг по сравнению с маслом, содержащим ионол.

Зависимость диэлектрических потерь в масле от концентрации воды в нем в присутствии и отсутствии сульфидов ДФС и ДЦГС показана на рис. 3.

Из рис. 3 видно, что наибольшим ингибирующим эффектом обладает ДЦГС по сравнению с ДФС и маслом, содержащим ионол.

При этом следует отметить, что образовавшиеся водорастворимые кислоты в процессе пребывания в аппарате [14] адсорбируются твердой изоляцией трансформатора, представляющей собой бумагу или электрокартон, что вызывает рост диэлектрических потерь в твердой изоляции.

Также было необходимо исследовать коррозионную активность исследуемых сульфидов по отношению к меди, как к 
наиболее активному металлу в конструкции трансформаторов[23]. Медь является предпочтительным проводящим материалом из-за ее стабильных физико-химических свойств и низкого удельного электрического сопротивления. Однако коррозия меди в электроэнергетическом оборудовании существует, то есть медь уязвима для отказов, связанных с коррозией.

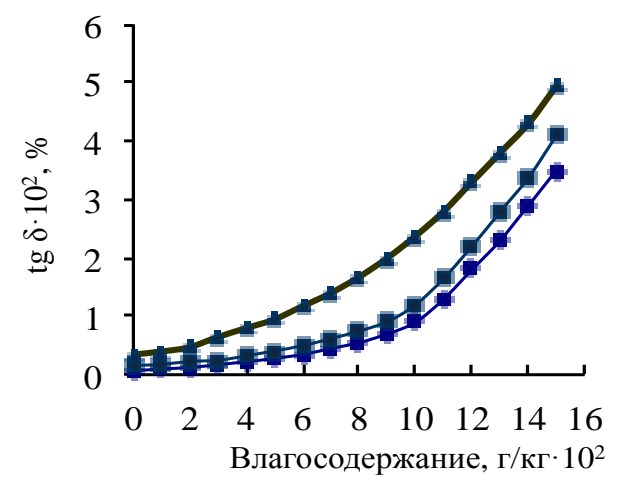

1 -масло ТС + $0.5 \%$ ДЦГС; 2 -масло ТС $+0.5 \%$ ДФС, 3 -масло с ионолом

Рис. 3. Влияние содержания воды на диэлектрические потери в масле TC. ${ }^{3}$

На следующем этапе было проведено исследование коррозионной активности индивидуальных сульфидов по ГОСТ 2917-76 на медных электролитических пластинках при температуре $100 \pm 1{ }^{\circ} \mathrm{C}$ в течение $180 \pm 5$ мин.

Одна медная пластинка использовалась в качестве эталона для сравнения изменения цвета экспериментальных пластинок. Экспериментальные пластинки погружали в модельные смеси на основе трансформаторного масла селективной очистки и индивидуальных сульфидов ДФС и ДЦГС. Для каждой модельной смеси использовали два образца в соответствии с ГОСТ 2917-76. Результаты эксперимента приведены на рис. 4 и 5.

По результатам испытания можно сделать вывод о том, что исследуемые индивидуальные сульфиды в трансформаторном масле селективной очитки не оказывают коррозионного воздействия на медные пластинки.

Проведенные исследования показали, что индивидуальные сульфиды ДЦГС и ДФС относятся К хорошим ингибиторам окислительного превращения углеводородов масла ТC, замедляющим скорость образования водорастворимых кислот и воды, снижающим кислотное число и образование осадка, что позволяет поддерживать необходимую степень надежности масляной изоляции маслонаполненного электрооборудования.

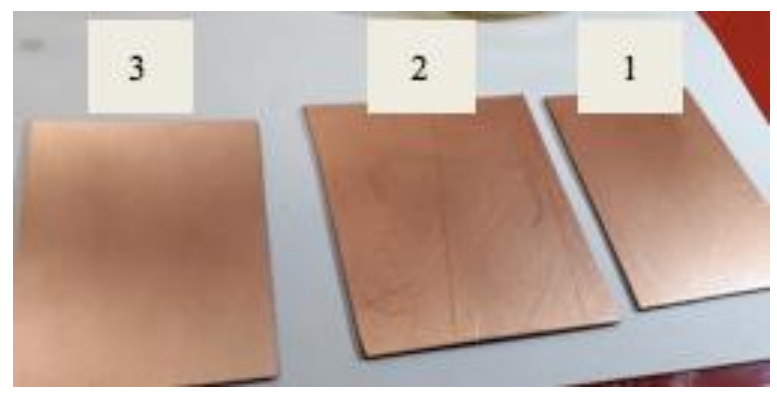

1, 2 - экспериментальные образцыь, 3 - эталон

Рис. 4. Исследование коррозионной активности ДФС ${ }^{4}$

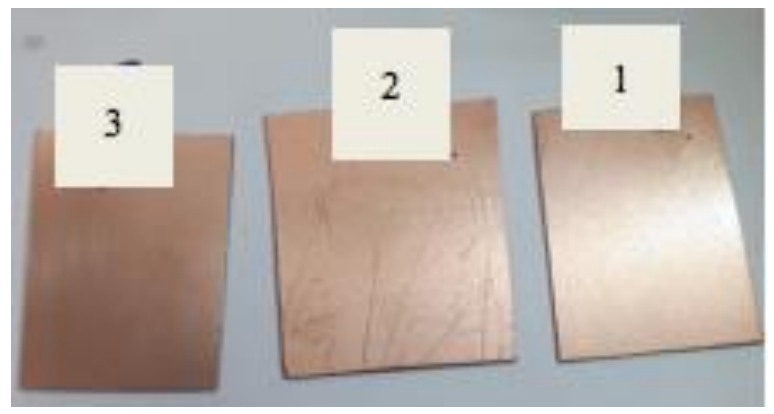

1, 2 - экспериментальные образиы, 3 - эталон (рисунок оторван от надписи под рисунком)

Рис. 5. Исследование коррозионной активности ДЦГС ${ }^{5}$

\section{ЗАКЛЮЧЕНИЕ}

1. Изучено влияние индивидуальных сульфидов - децилциклогексилсульфида и децилфенилсульфида на показатели стабильности против окисления масла и электрические характеристики трансформаторного масла селективной очистки.

2. Установлено, что при окислении углеводородов масла в электрическом поле напряженностью 30 кВ/см, во-первых, оба исследуемых сульфида проявили ингибирующие свойства, во-вторых, децилциклогексилсульфид обладает большими ингибирующими свойствами по сравнению с децилфенилсульфидом, о чем свидетельствует меньшее количество образовавшейся воды в 1.89 раза по сравнению с децилфенилсульфидом, водо- 
растворимых кислот соответственно в 2.22 раза, а также снижение кислотного числа и массовой доли осадка

3. Показано, что электрическая прочность трансформаторного масла при повышенном влагосодержании в присутствии децилциклогексилсульфида выше, чем в присутствии децилфенилсульфида, а диэлектрические потери в масле соответственно ниже.

4. Исследование коррозионной активности сульфидов показало, что независимо от химической структуры они не оказывают коррозионного воздействия на медные пластинки.

\section{Библиография (References)}

[1] Transformer Oil Market. Available at: https://www.marketsandmarkets.com/MarketReports/transformer-oil-market-967.html (accessed 01.10.2021)

[2] Maina R., Tumiatti V., Pompili M., Bartnikas R. Corrosive Sulfur Effects in Transformer Oils and Remedial Procedures. IEEE Transactions on Dielectrics and Electrical Insulation, 2010, vol. 16(6), pp. 1655-1663doi:10.1109/TDEI.2009. 5361586

[3] Dessouky S.S., El-Faraskoury A., Haassan A., Ghoneim S. M.Further Contribution for Evaluating the Aging of Transformer oil of Power Transformer. JES. Journal of Engineering Sciences, 2015, vol. 43, No 2, pp. 211-226. doi: 10.21608/ JESAUN.2015.115168.

[4] Wang Y., Gong S., Grzybowski S. Reliability Evaluation Method for Oil-Paper Insulation in Power Transformers. Energies, 2011, vol. 4(9), pp. 1362-1375. doi.org/10.3390/en4091362.

[5] Chen S., Chen Yu., Yu N., Pang X., Zhang L., Han Z., Feng G., Jia Yu., Xu T. [Aging Analysis of Transformer Mineral Insulating Oil Based on Chromatographic Furfural Content Determination]. IOP Conference Series: Materials Science and Engineering, Volume 493, 2nd International Conference on Frontiers of Materials Synthesis and Processing. Sanya, 2018. (in English).

[6] GadzhievM.Kh., IsakaevE.Kh., Tyuftyaev A.S., Akimov P.L., Yusupov D.I., Kulikov Yu.M., Panov V.A. Electrical Breakdown of Transformer Oil with Sulfur Hexafluoride and Air Bubbles. Technical Physics. 2015, vol. 60(7), pp. 11011103. doi:10.1134/S1063784215070117.

[7] Safiddine L.,Zafour H., Mohan Rao U., Fofana I. Regeneration of Transformer Insulating Fluids Using Membrane Separation Technology. Energies.2019, vol. 12(3), p. 368. doi.org/10.3390/ en12030368.

[8] Lelekakis N., Martin D., Wijaya J., Susa D. The Effect of Acid Accumulation in PowerTransformer Oil on the Aging Rate of Paper In- sulation. IEEE Electrical Insulation Magazine. 2014, Vol. 30(3), pp. 19-26. doi:10.1109/MEI.2014.6804738.

[9] Chairul I.S., Abu Bakar N., Ab Ghani S., Rahim N.H., Ab Aziz N.H. Effect of Acids Formation on the Breakdown Voltage Properties of Transformer Insulating Oil. IOP Conference Series Materials Science and Engineering. Perlis, 2020, vol. 767. doi:10.1088/1757-899X/767/1/012063.

[10]Phalphale A., Bhagat K., Nagare S. Investigation of Transformer Oil Exposed to the Atmosphere. International Journal of Management, Technology And Engineering. 2018, vol. 8, Is. XI, pp. 706713.doi: 10.13140/RG.2.2.28041. 29280.

[11] Sing J., Sing S. Transformer Failure Analysis: Reasons and Methods. International Journal of Engineering Research \& Technology (IJERT). ACMEE - 2016 Conference Proceedings. 2016, vol.4, Is.5.

[12] Cristiana Aj., Salam M.A., Rahman Q.M., Fushuan Wen., Ang S.P., Voon W. Causes of Transformer Failures and Diagnostic Methods. Renewable and Sustainable Energy Reviews. 2018, vol. 82, part 1, pp. 1442-1456. doi.org/ 10.1016/j.rser.2017.05.165.

[13] Gutten M., Šebok M., Korenčiak D., Brnčal P., Kubis M., Żukowski P., Koltunowicz T. N. Diagnostika Chastotnoy Oblasti Izolyatsii Transformatora [Frequency Domain Diagnostics of Transformer Insulation]. Pribory i Metody Izmerenii - Devices and Methods of Measurements, 2019. (InRussian). doi: 10.21122/2220-95062019-10-4-353-359.

[14] Dielektricheskaya Prochnost' Transformatornogo Izolyatsionnogo Masla. [Dielectric Strength of Transformer Insulating Oil]. Available at:http://oilregeneration.globecore.com/dielectricstrength-of-transformer-oil-2. (accessed 23.09. 2021).

[15] Komarov V.B., L'vova M.M. Izmenenie Pokazatelei Transformatora i Transformatornogo Masla v Protsesse Dlitel'noi Eks-pluatatsii Silovykh Transformatorov i Avtotransformatorov [Changes in Insulation and Transformer Oil Indicators During Long-Term Operation of Power Transformers and Autotransformers]. ELECTRO Electrical Engineering Electrical Power Engineering Electrical Industry - ELEKTRO Elektrotekhnika Elektroenergetika Elektrotekhnicheskaya promyshlennost', 2014. No. 5. pp. 44-49. (In Russian).

[16]GOST 982-80. Masla Transformatornye. Tekhnicheskie Usloviya [State Standard 982 - 80. Transformer Oils. Technical Conditions]. Moscow, Standartinform Publ., 2011. 7 p.

[17] Gainullina L R., Tutubalina V.P. [Influence of the Additives of Natural Sulphur-Organic Compounds on Thermal Stability of oil Fractions of Arlan Petroleum]. IOP Conf. Ser.: Mater. Sci. 
Eng. 2018, p.412. doi:10.1088/1757899X/412/1/012016. (In English).

[18] Babalola F.U., Susu A.A. Pre-Treatment of Heavy Crude Oils for Refining. 4th International Sustainable Buildings Symposium. 2019. doi: 10.5772/intechopen.87836.

[19] Suwarno, Prakoso M. H. Effects of Water Content on Dielectric Properties of Mineral Transformer Oil. World Academy of Science, Engineering and Technology International Journal of Electrical and Computer Engineering. 2015, vol. 9. No. 10, pp. 1142-1146.

[20] Buerschaper B., Kleboth-Lugova O., Leibfried T. The Electrical Strength of Transformer Oil in a Transformer board-Oil System during Moisture Non-Equilibrium. Conference: Electrical Insulation and Dielectric Phenomena, 2003. doi:10.1109/CEIDP.2003.1254845.

[21] Tyuryumina A., Batrak A., Sekacsiy V. [Determination of Transformer Oil Quality by the Acoustic Method]. 12-ya MezhdunarodnayaNauchno-Tekhnicheskaya KonferentsiyapoElektromekhanike i Robototekhnike «Zavalishinskie Chteniya» - 2017. [12th International Scientific-Technical Conference on Electromechanics and Robotics "Zavalishin's Readings" - 2017]. MATEC Web of Conferences113, (2017). doi: $10.1051 /$ matecconf/201711301008

[22]] Mahmud S. Influence of Contamination on the Electrical Performance of Power Transformer Oil. Doctoral Thesis. Southampton, 2015. 171 p.
[23] Gao S., Yang L., Deng B., Zhang J. Corrosion Mechanism for Local Enrichment of Acids and Copper Ions in Copper-Insulating Paper Contacts Leading to the Acceleration of Copper Sulfide Formation Induced by Dibenzyl Disulfide. Royal Society of Chemistry. 2017, vol. 7, pp. 5247552485. doi: 10.1039/C7RA10816H.

\section{APPENDIX1 (ПРИЛОЖЕНИЕ 1)}

1Fig. 1. Sulfide concentration effect on the amount of absorbed oxygen 1 -DCHS, 2- DFS

Key: The absorbed oxygen amount, $\mathrm{ml} / 100 \mathrm{~g}$ of oil; Sulfide concentration.

${ }^{2}$ Fig. 2.2. Water content in oil effect on its dielectric strength (1 - oil with ionol, 2 - TS oil + 0.5\% DFS, 3 TS oil + 0.5\% DCHS).

Key: Moisture content $\mathrm{g} / \mathrm{kg} 10^{2}$;

Oil electric strength, $\mathrm{kV} / \mathrm{cm}$.

${ }^{3}$ Fig. 3. Influence of water content on dielectric losses in vehicle oil ( 1 - TS oil + 0.5\% DCGS; 2 - TS oil + $0.5 \%$ DFS, 3 - oil with ionol).

Key: Moisture content g/kg $10^{2}$.

${ }^{4}$ Fig. 4. Investigation of DFS corrosiveness.1, 2 - experimental samples, 3 - standard.

${ }^{5}$ Fig. 5. Investigation of DCHS corrosiveness. 1, 2 experimental samples, 3 - standard.

${ }^{6}$ Table. Amount of water formed in the transformer oil in the presence and absence of individual sulfides, after the oxidation of oil hydrocarbons in the apparatus.

\section{Сведения об авторе.}

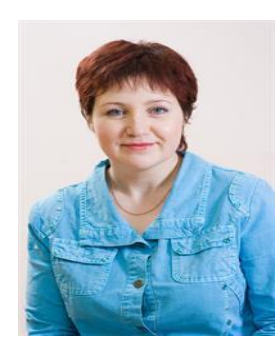

Гайнуллина Лейсан Раисовна, к.т.н., доцент кафедры «Возобновляемые источники энергии» Казанского государственного энергетического университета.

Область научных исследований: повышение эксплуатационных характеристик трансформаторного масла.

E-mail:gainullina7819@mail.ru 